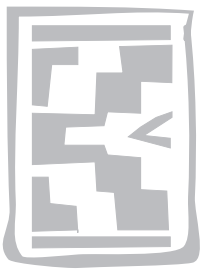

\title{
Association of trypanosomosis risk with dairy cattle production in western Kenya
}

\author{
G.L. MUGUNIERI* and G.O. MATETE \\ KARI - Trypanosomosis Research Center, P.O. Box 362, Kikuyu 00902, Kenya
}

\begin{abstract}
MUGUNIERI, G.L. \& MATETE, G.O. 2005. Association of trypanosomosis risk with dairy cattle production in western Kenya. Onderstepoort Journal of Veterinary Research, 72:279-284

Dairy cattle reared in western Kenya are exposed to medium to high levels of trypanosomosis risk. The social background, farm characteristics and dairy cattle productivity of 90 and 30 randomly selected farmers from medium- and high-risk trypanosomosis areas, respectively, were compared. All the 120 farmers were visited between July and August 2002. Data analysis was performed using descriptive statistics and analysis of variance. The results showed that increased trypanosomosis risk represented by an increase in disease prevalence in cattle of $1 \%$ to $20 \%$ decreased the density of dairy cattle by $53 \%$ and increased the calving interval from 14 to 25 months. The increased risk was also associated with a significant increase in cattle mortalities and in a lactation period of 257 to 300 days. It was concluded that removal of the trypanosomosis constraint on dairy production would lead to expansion of dairying since the domestic demand for dairy products is expected to increase.
\end{abstract}

Keywords: Dairy cattle, Kenya, production, trypanosomosis risk

\section{INTRODUCTION}

Dairy production in Kenya is dominated by smallholder farmers who contribute about $85 \%$ of total milk produced (Peeler \& Omore 1997). It is estimated that the dairy herd in Kenya comprises about 3 million head of cattle, of which 2.5 million are owned by smallholders numbering about 650000 (MoA 1996). This implies that this sector employs many people who derive a regular source of income and have a balanced nutrition. The sector is a catalyst for economic development and, when compared to other agricultural activities, it has higher financial returns (Mclntire, Bourzat \& Pingali 1992).

\footnotetext{
* Author to whom correspondence is to be addressed. E-mail: ketri@africaonline.co.ke

Accepted for publication 14 June 2005-Editor
}

Dairy cattle production constraints have been extensively described by various authors (Stotz 1983; Moll, Lohding \& Young 1984; Maloo, Thorpe, Ngumi \& Perry 1994; Peeler \& Omore 1997). These studies have identified livestock diseases as one of the major constraints to dairy production in Kenya. Major diseases cited are tick-borne diseases (TBDs) and trypanosomosis. Some field studies have attempted to ascertain the actual incidence and impact of TBDs on dairy production (Gitau, O'Callaghan, McDermott, Omore, Odima, Mulei \& Kilungu 1994; Maloo et al. 1994). However, there exists only very limited information that measures the losses associated with trypanosomosis and the benefits that can accrue after its effective control (Mbogoh \& Mukhebi 1997). This study provides some information on the losses associated with trypanosomosis among dairy farmers in western Kenya which could be used in designing sustainable strategies for managing the disease in future control programmes in this region. 


\section{MATERIALS AND METHODS}

\section{Study area}

The study region was stratified into two zones having different levels of trypanosomosis risk based on the prevalence of the disease in cattle for the period 1996-1999. It was assumed that the trypanosomosis risk prevailing between these years influenced production decisions of the subsequent years under study. Following the outbreak of bovine trypanosomosis in western Kenya in the late 1980s (Angus 1996), the Kenya Trypanosomiasis Research Institute (KETRI) initiated routine trypanosomosis surveillance studies in this region, under a larger programme that was funded by the Department for International Development (DfID) of the United Kingdom (KETRI 1994). Under this programme cattle, randomly sampled in selected villages on a quarterly basis, were screened for the presence of trypanosome parasites, using the standardized protocols for the microhaematocrit centrifugation-buffy coat technique, and thick and film blood smears (Woo 1969). On the basis of this data, this investigation categorized the study region into zones of medium and, from which farmers were sampled for data collection. A sampling frame consisting of dairy farmers in each zone was constructed with the assistance of local animal health and provincial administration staff and village elders. The medium risk zone consisted of three administrative divisions with an estimated area of about $377 \mathrm{~km}^{2}$ and had 238 dairy farmers. The high-risk zone comprised one administrative division with an area of about $92 \mathrm{~km}^{2}$ and had 39 dairy farmers. From this list of farmers, 120 were randomly sampled, 90 being from the mediumrisk zone and 30 from the high-risk area. The sample size was determined by resource availability. Information on each of these trypanosomosis risk zones is given in Table 1.

\section{Data collection}

Each of the 120 farms was visited once between July and August 2002. During the visit, a comprehensive pre-tested questionnaire was administered. Data were collected on the individual farmer and farm characteristics, cattle nutrition and grazing management, farm enterprises, farm inputs and revenues, and general livestock management issues. A detailed account of each commodity produced on the farm listing all inputs and their costs, outputs and prices was tabulated. Data on the management practices were verified by physical inspection of assets and farm records at the time of the interview. All the farmers under survey were enrolled under the National Dairy Development Project (NDDP), and farm kept records detailing milk production, fertility performance and mortalities.

\section{Data analysis}

Descriptive statistics were used to describe and summarize dairy cattle density and productivity indicators. Analysis of variance was used to compare productivity of livestock under different levels of trypanosomosis risk. Productivity analysis was based on the premise that improved livestock health management may increase productivity of cattle (CARD 1989; Mugunieri, Omiti \& Irungu 2004). The impact of trypanosomosis risk on the success that cattle keepers have achieved while engaging in dairy production can be obtained by:

\section{(a) Comparing the peak milk output per animal under different trypanosomosis risk}

All other factors being equal between the two zones, the peak milk output per animal was taken as a proxy for productivity of animals reared by farmers under varying trypanosomosis risk levels. The measurements of milk production were obtained from the records kept by farmers, all of whom were enrolled under the NDDP. The peak milk output average (for all animals kept) was compared across the two trypanosomosis risk levels.

\section{(b) Calculating the calving rate under different trypanosomosis risk conditions}

This study estimated the ratio of births to the number of adult females in the herd in each calendar year between 1999 and 2002. This was named the "calving rate" (CR).

$\mathrm{CR}=\mathrm{LB} / \mathrm{AF}$, where $\mathrm{CR}=$ calving rate $\mathrm{LB}=$ number of births in a specified period and $A F=$ number of adult females in the herd in a specified time period.

\section{(c) Comparing dairy cattle densities under different trypanosomosis risk}

The number of dairy animals per farmer was estimated over a period of 3 years (1999, 2000 and 2001). The average of the annual means for the 3 years expressed as total livestock units (TLU) was taken as the average number of dairy animals per farmer. The computation of the TLU was based on figures in ILCA (1990). This was then multiplied by the total number of farmers engaging in dairying to yield the approximate total number of dairy animals for each region. The ratio between this computed value and size (area) of the region in $\mathrm{km}^{2}$ gave an 
TABLE 1 Summary information on study divisions

\begin{tabular}{|c|c|c|c|c|c|c|}
\hline $\begin{array}{l}\text { Division } \\
\left(\text { size } \mathrm{km}^{2}\right)\end{array}$ & Year & $\begin{array}{l}\text { Villages } \\
\text { sampled per } \\
\text { visit }^{\star}\end{array}$ & $\begin{array}{l}\text { Mean number of } \\
\text { cattle sampled per } \\
\text { visit }\end{array}$ & $\begin{array}{l}\text { Average annual } \\
\text { prevalence } \\
(\%)\end{array}$ & $\begin{array}{l}\text { Ascribed } \\
\text { trypanosomosis } \\
\text { risk }\end{array}$ & $\begin{array}{l}\text { Dairy farmers } \\
\text { population } \\
\text { size }\end{array}$ \\
\hline $\begin{array}{l}\text { Malakisi } \\
(101.4)\end{array}$ & $\begin{array}{l}1996 \\
1997 \\
1998 \\
1999\end{array}$ & $\begin{array}{l}4 \\
4 \\
3 \\
4\end{array}$ & $\begin{array}{l}48.7(24.39) \\
73.5(7.76) \\
57.7(14.84) \\
70.0(14.10)\end{array}$ & $\begin{array}{l}0.25(0.50) \\
4.75(5.62) \\
2.67(1.15) \\
6.75(1.71)\end{array}$ & Medium & 82 \\
\hline $\begin{array}{l}\text { Matayos } \\
(173.7)\end{array}$ & $\begin{array}{l}1996 \\
1997 \\
1998 \\
1999\end{array}$ & $\begin{array}{l}4 \\
4 \\
4 \\
4\end{array}$ & $\begin{array}{r}59.2(18.94) \\
55.5(24.37) \\
53.7(26.92) \\
105.2(42.18)\end{array}$ & $\begin{array}{l}4.50(4.20) \\
3.00(2.16) \\
5.75(2.87) \\
3.00(1.15)\end{array}$ & Medium & 78 \\
\hline $\begin{array}{l}\text { Amagoro } \\
(91.7)\end{array}$ & $\begin{array}{l}1996 \\
1997 \\
1998 \\
1999\end{array}$ & $\begin{array}{l}4 \\
8 \\
8 \\
8\end{array}$ & $\begin{array}{l}64.5(19.82) \\
61.2(32.65) \\
52.4(24.30) \\
68.6(27.34)\end{array}$ & $\begin{array}{l}21.00(19.35) \\
19.50(11.86) \\
18.00(12.52) \\
26.00(15.06)\end{array}$ & High & 39 \\
\hline $\begin{array}{l}\text { Funyula } \\
(101.4)\end{array}$ & $\begin{array}{l}1996 \\
1997 \\
1998 \\
1999\end{array}$ & $\begin{array}{l}3 \\
4 \\
4^{+} \\
4\end{array}$ & $\begin{array}{l}83.3(51.14) \\
38.7(21.53) \\
50.0 \\
100.0(49.21)\end{array}$ & $\begin{array}{l}4.00(3.46) \\
7.00(2.71) \\
4.50(4.12) \\
3.75(1.26)\end{array}$ & Medium & 70 \\
\hline
\end{tabular}

Values in parenthesis are standard deviations

Sources: Angus 1996; KETRI 1999

* Four visits made per year

+ Data for one visit only

indicator of the dairy cattle density (DCD) per $\mathrm{km}^{2}$ for each trypanosomosis risk region.

\section{RESULTS AND DISCUSSION}

\section{Farmer and farm characteristics under varying trypanosomosis risk}

The farmer and farm characteristics across the two trypanosomosis risk zones are given in Table 2.

Farmers were on average 47 years old and owned 6.6 acres of land. There were no significant differences in distances to the nearest market and artificial insemination or breeding bull services across the two trypanosomosis risk zones.

There were no significant differences in the number of visits made to attend to TBDs. There was also $100 \%$ positive response with regard to use of acaricides in the management of ticks. This implied that TBDs may not have been confounding factors in variation in productivity and practices between the two risk zones. Trypanosomosis treatment visits were also not significantly different between the two risk areas, but there appeared to have been a more rigorous application of insecticides for vector control in the high-risk areas. It was difficult to compare the costs incurred in treatment of these ailments as farmers were served by different cadres of veterinary personnel who charged different fees even for similar recorded cases.

The predominant grazing system practised in the high-risk trypanosomosis area was a small-scale, intensive grazing system, alternatively called the zero-grazing system. This system was used by $28 \%$ and $87 \%$ of farmers in the medium- and highrisk areas, respectively. The remainder of the farmers used the semi-intensive system that is also called the paddock-grazing management (Peeler \& Omore 1997).

The zero-grazing system was developed in Kenya to solve the constraint of land scarcity and improve milk production (De Jong 1996). It is a capital and labour intensive system where exotic breeds and their crosses are kept under intensive grazing, mainly for commercial dairy purposes. Animals are confined in housing units where they are stall fed with fodder cut from the field. Manufactured feeds are also widely used, especially at milking. On the other hand, under the paddock system, exotic cattle breeds and their crosses graze on natural pastures usually supplemented with cultivated fodder. Purchased inputs such as manufactured feeds and veterinary services are widely employed in the production process. It appears that increased trypanosomosis risk necessitated investments in capital- 
Association of trypanosomosis risk with dairy cattle production in Kenya

TABLE 2 Farm and farmer characteristics under varying trypanosomosis risk

\begin{tabular}{|l|l|l|}
\hline \multirow{2}{*}{ Characteristic (means/frequency) } & \multicolumn{2}{l|}{ Trypanosomosis risk } \\
\cline { 2 - 3 } & Medium risk $(n=90)$ & High risk $(n=30)$ \\
\hline Land size (acres) & 7.86 & 7.80 \\
Household size (number) & 8.43 & 11.03 \\
Crop gross margin per acre per year & 427 & 503 \\
Off-farm income per month (Kshs) & $2083^{*}$ & $8303^{*}$ \\
Pasture feed size (acres) & 1.76 & 1.36 \\
Years of experience in dairying & 8.90 & 5.80 \\
Mature female dairy animals & $2.45^{+}$ & $1.80^{+}$ \\
Household head age (years) & 50.7 & 46.7 \\
TBDs treatment visits (2001/02) & 3.06 & 3.83 \\
Trypanosomosis treatment visits (2001/02) & 3.42 & 3.43 \\
Trypanocidal drugs use (\% frequency of farmers who used dugs) & 58 & 63 \\
Insecticide applied on cattle (\% frequency of farmers who used pour-on) & 28 & 60 \\
\hline
\end{tabular}

Values with the same superscript are significantly different between groups $(P=0.05)$

TABLE 3 Relation between dairy cattle density indicators and trypanosomosis risk

\begin{tabular}{|l|l|l|}
\hline \multirow{2}{*}{ Characteristic } & \multicolumn{2}{l}{ Level of trypanosomosis risk } \\
\cline { 2 - 3 } & Medium & High \\
\hline Size of region (km²) & 539.3 & 91.7 \\
Households in the region (no.) & 34951 & 7617 \\
Population in the region & 165103 & 33954 \\
Population density (persons per km $\left.{ }^{2}\right)$ & 306.1 & 370.3 \\
Dairying households (approximate) & 230 & 39 \\
Mean HH dairy cattle numbers (3-year average for means) & $3.56^{*}(\mathrm{SD} \pm 2.5 ; n=93)$ & $2.30^{*}(\mathrm{SD} \pm 2.10 ; n=29)$ \\
Dairy animals (approximate) & 819 & 90 \\
Dairy cattle density (DCD) (no. per km²) & 1.5 & 0.98 \\
Household undertaking dairying (\%) & 0.70 & 0.50 \\
Peak milk output (l/day) & $7.3^{*}(\mathrm{SD} \pm 4.0)$ & $9.6^{*}(\mathrm{SD} \pm 4.6)$ \\
Lactation period (days) & $257.64^{+}(\mathrm{SD} \pm 32.95)$ & $300^{+}(\mathrm{SD} \pm 73.93)$ \\
Calving ratio (CR) & $0.83^{*}(\mathrm{SD} \pm 0.25)$ & $0.47^{*}(\mathrm{SD} \pm 0.30)$ \\
Deaths per farmer per year (3-year average) & $0.009^{*}(\mathrm{SD} \pm 0.05)$ & $0.052^{*}(\mathrm{SD} \pm 0.12)$ \\
\hline
\end{tabular}

Values with the same superscript are significantly different between groups $(P=0.05)$

intensive grazing systems in the form of construction of dairy cattle housing units, when an opportunity existed to use the less capital-intensive system by utilizing the most abundant resource (land). The use of the zero-grazing system when land was not a constraint, acted as an insurance against increased production risk by minimizing animal-tsetse contact. This implied that dairying became an enterprise for households with higher income, which was supported by the fact that off-farm income of dairy farmers in high-risk trypanosomosis areas was significantly higher.

\section{Dairy cattle density, calving rate and milk productivity}

The average dairy herd size was 3.2 animals $(S D=$ 2.4) (Table 3), computed as the three-year average of the annual means that were derived for the years 1999, 2000 and 2001.

The herd consisted mainly of mature cows, heifers and calves. The DCD was 1.5 TLU in the mediumrisk areas compared to 0.98 TLU in the high-risk zone. The mean peak milk output per animal (computed as the mean of peak milk yield attained per cattle) was significantly higher $(P<0.05)$ for the high-risk trypanosomosis area. Based on the computation of the calving rate, an average of 0.8 births per female per year was recorded for the mediumrisk trypanosomosis areas as compared to 0.5 births per female per year for the high-risk areas. This translated to a calving interval of 14 months for the medium-risk as compared to 25 months for the highrisk areas. Consequently, the average lactation period for cattle in the medium-risk area was significant- 
ly shorter. The average mortalities per farmer were significantly higher in the high-risk area.

The differences in the peak milk output per day attained between the two trypanosomosis risk zones could be due to two factors. This could be a proxy of the quality of animals reared between the two zones. Alternatively, the quality of animals could have been the same but differences in productivity could be due to the intensive production systems employed by farmers in the high-risk area. The longer lactation period and higher mortality rates in the high-risk areas may have been due to the impact of the disease. This is in concordance to the knowledge that increase in trypanosomosis risk often prolongs the calving interval due to abortions, early embryonic deaths and silent heat (Swallow 2000). Other factors that might influence the calving interval, such as physical access to breeding services (artificial insemination and bulls), were not significantly different.

\section{CONCLUSION}

The dairy sector in Kenya is the most developed in eastern and central Africa, making the country self sufficient in major dairy products, except in periods of drought (Omiti \& Muma 2001). However, it is projected that by the year 2010, demand for dairy products will outstrip supply if urgent measures to sustain growth in production are not undertaken (Peeler \& Omore 1997). Expanding production in areas with potential that are currently under-exploited provides one of the avenues to increase production. Trypanosomosis is one of the major constraints limiting production in these areas. This study has shown that trypanosomosis risk alters the grazing management system used and makes dairy farming expensive. Increased trypanosomosis risk represented by an increased prevalence of $1 \%$ to $20 \%$ decreased the density of dairy animals by about $53 \%$ and was associated with an increase of calving interval from about 14 to 25 months among the dairy farmers.

The most common method used for the control of tsetse flies by dairy farmers was insecticide application (pour-on preparations) on their cattle. Trypanocidal drugs were the main control method used in management of the disease. Farmers stocked these drugs, which animal health personnel used for treating their animals. The private use of drugs to control trypanosomosis has become popular among the farmers in most trypanosomosis-endemic areas of Kenya (ILRAD 1994; Mugunieri \& Murilla 2003). In addition, the use of insecticide-treated cattle has also become very common, unlike the use of artificial baits (traps and targets), which have not gained popularity in the absence of concerted support from governmental or non-governmental organizations (Eisler, Torr, Machila, Coleman \& Morton 2002). It is suggested that this contrast reflects, at least in part, the differences in public and private benefits. On the one hand, use of drugs confers an entirely private benefit, which is immediately effective even when a single farmer treats a single cow. On the other, the benefits of artificial baits are largely public and only realized when large numbers of individuals work in a concerted manner over a large area for a relatively long period. Application of insecticides on cattle has a mix of public and private benefits. Capitalizing on the perceived private and visible benefits of insecticide-treated cattle; this approach can be promoted for wide application to complement the use of drugs in the management of trypanosomosis. It is recommended that appropriate means of promoting its use by farmers and rural communities should be devised by the government. This will not only ameliorate the risk imposed by trypanosomosis on farmers currently undertaking dairying, but will see expansion of the enterprise to ensure that the country remains self-sufficient in the dairy products.

\section{ACKNOWLEDGEMENTS}

The World Bank under the Kenya Agricultural Research Institute-Agricultural Research Fund Program funded this research. This article is published with permission of the Center Director, KARI-TRC.

\section{REFERENCES}

ANGUS, S.D. 1996. The epidemiology of trypanosomosis in village livestock in an endemic sleeping sickness area of western Kenya. Ph.D. thesis, University of Glasgow.

CARD [Coordinated Agricultural and Rural Development] 1989. Small ruminants in Zimbabwe, a review of functions, research and proposals for communal lands. Discussion paper. Masvingo, Zimbabwe: Belmont Press.

DE JONG, R. 1996. Dairy stock development and milk production with smallholders. Ph.D. thesis, Wageningen Agricultural University.

EISLER, M., TORR, S., MACHILA, N., COLEMAN, P. \& MORTON, J. 2002. Integrated control of ticks and tsetse: epidemiological, social and economic implications. Integrated Control of Pathogenic Trypanosomes and their Vectors (ICPTV) (Newsletter no. 6:7-8).

GITAU, G.K., O'CALLAGHAN, C.J., MCDERMOTT, J.J., OMORE, A.O., ODIMA, P.A., MULEI, C.M. \& KILUNGU, J.K. 1994. Health and productivity of cattle in smallholder dairy farms in Kiambu district, Kenya: Study design and farm description. Preventive Veterinary Medicine, 21:155-166. 
ILCA [International Livestock Centre for Africa] 1990. Working paper 1. Livestock systems research manual. Vol. 1. Addis Ababa Ethiopia: International Livestock Centre for Africa.

ILRAD 1994. Annual Reports. Nairobi.

KETRI 1994. KETRI/ODA Trypanosomiasis Research Project Phase III, 1994-1997. Muguga.

KETRI 1999. Surveys and investigations. Reports from Busia, Bungoma, Siaya and Transmara Districts. Muguga (Technical Team Report, no. 1 of 1999).

MALOO, S.H., THORPE, W., NGUMI, P.N. \& PERRY, B.D. 1994. Systematic epidemiological studies to identify and resolve constraints to smallholder dairy production in coastal lowlands of Kenya. The Kenya Veterinarian, 18:359.

MBOGOH, S.G. \& MUKHEBI, A.W. 1997. Evaluation of the role of, programme and resource requirements of the SocioEconomics Unit of KETRI. Consultancy Report. KETRI/ODA Trypanosomosis Research Project Phase III. KETRI, Kikuyu.

MCINTIRE, J., BOURZAT, D. \& PINGALI, P. 1992. Crops livestock interaction in sub-Saharan Africa. Washington DC: World Bank.

MOA [Ministry of Agriculture] 1996. Annual Report. Department of Animal Production. Hill Plaza, Nairobi.

MOLL, G., LOHDING, A. \& YOUNG, A.S. 1984. Epidemiology of theileriosis in the Transmara division, Kenya: Husbandry and disease background and preliminary investigations on theileriosis in calves. Preventive Veterinary Medicine, 2:801-831.
MUGUNIERI, G.L. \& MURILLA, G.A. 2003. Resistance to trypanocidal drugs-suggestions from field survey on drug use in Kwale district, Kenya. Ondestepoort Journal of Veterinary Research, 70:29-36.

MUGUNIERI, G.L., OMITI, J.M. \& IRUNGU, P. 2004 Performance of community-based animal health workers in the delivery of livestock health services. Tropical Animal Health and Production, 36:523-535.

OMITI, J.M. \& MUMA, M. 2000. Policy and institutional strategies to commercialize the dairy sector in Kenya. Nairobi: Institute of Policy Analysis and Research (IPAR) (Occasional paper, no. 006/2000).

PEELER, E.J. \& OMORE, A.O. 1997. Manual of livestock production systems in Kenya, $2^{\text {nd }}$ ed. KARI/DFID National Agricultural Research Project II. Kikuyu, Kenya: National Veterinary Research Centre.

STOTZ, D. 1983. Production techniques and economics of smallholder livestock production systems in Kenya: Farm Management Handbook of Kenya. Nairobi: Ministry of Livestock Development.

SWALLOW, B.M. 2000. Impacts of trypanosomosis on African Agriculture. Programme Against African Trypanosomiasis (PAAT). Rome: FAO (Technical and Scientific Series, 2).

WOO, P.T.K. 1969. The haematocrit centrifugation for the detection of trypanosomes in blood. Canadian Journal of Zoology, 47:921-923. 